\title{
Simplified Mix Design Procedures for Steel Fibre Reinforced Self Compacting Concrete
}

\author{
Abibasheer Basheerudeen and Sivakumar Anandan* \\ Structural Engineering Division, SMBS, VIT, Vellore, Tamilnadu, India \\ *E-mail: sivakumara@vit.ac.in
}

\begin{abstract}
The present study focus on the systematic design methodology for producing a self-compacting concrete (SFRSCC) consisting of steel fibre reinforcements. It is intended to achieve a self-consolidating concrete which can yield dual benefit of self-consolidating properties as well as toughness of the composite. Experimental modelling consisted of designing the mortar phase using manufactured sand (M-sand) as fine aggregate using systematic mix design methodology based on particle packing concept. Optimisation of aggregates was arrived based on packing density concept by conducting slump cone studies. Powder combinations consisting of cement and ground granulated blast furnace slag (GGBFS) were selected by conducting paste consistency test. Finally, superplasticizer dosage was fixed based on Marsh cone studies and volume fraction of steel fibres from slump flow studies. The workability of standard and high strength concrete is affected by the inclusion of steel fibre dosage and the fresh properties revealed the importance of maintaining a high paste volume for better flow ability. Based on the proposed mix design methodology with M-sand a high strength self-compacting concrete was achieved upto $70 \mathrm{MPa}$. Experimental investigations were reported on the other assessment made from fresh and hardened properties of designed self-compacting steel fibre concrete mixes. Also, the outcome of test results revealed the possibility of using M-sand as an alternative for complete replacement of river sand.
\end{abstract}

Keywords: Self compacting concrete, particle packing, manufactured sand, steel fibres, compressive strength, elastic modulus.

ENGINEERING JOURNAL Volume 19 Issue 1

Received 21 March 2014

Accepted 13 August 2014

Published 30 January 2015

Online at http://www.engj.org/

DOI:10.4186/ej.2015.19.1.21 


\section{Introduction}

The tremendous growth in the infrastructure necessitates the use of quality concrete to serve for long term performance. However, a major setback in the construction industry is the expensive construction materials and early deterioration of conventional concrete due to inappropriate concrete design. One of the criteria for accomplishing a durable concrete is by achieving high quality concrete by using simple design methodology. But, the shortage of skilled employees has led to diminution in the quality of construction work. The best method for overcoming this problem is by employing of Self compacting concrete is (SCC), Divya, et al. 2010 [1]. Compared to conventional concrete, SCC is a concrete which is able to flow under its own weight, completely filling the formwork, even in the presence of congested reinforcement, without any mechanical vibration. Hardened SCC exhibits improved mechanical properties compared to conventional vibrated concrete [2]. The concrete also exhibited high flowability and resistance to segregation in both static and dynamic conditions, Nanthagopalan, et al. 2010 [3]. Over two decades, considerable research work was carried out in SCC. There were many mix design methods proposed by various researchers around the world and the first mix design methodology was proposed by Okamura, et al. 1993 [4]. The fresh and hardened properties of concrete are greatly influenced by the appropriate selection of aggregates. Shape and texture of fine aggregates plays a vital role on the resulting SCC than coarse aggregate, Quiroga, et al. 2003 [5]. The most commonly used material as fine aggregate is the natural river sand, which occurs in the river beds. Mining of sands from the river beds has catastrophic environmental impacts, which led to the exploration for a suitable alternate material. Manufactured sand (M-sand) obtained by crushing rocks to the required grain size distribution is an effective alternative to river sand. The amount of fines content in $\mathrm{M}$-sand are more and the fines are composed of rock dust rather than silts and clays in the case of natural river sand, Venkatarama, et al. 2011 and Nanthagopalan, et al. 2011 [6-7]. As per Indian standards, the

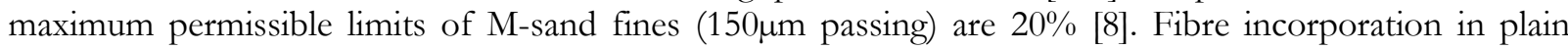
concrete decreases the brittle fracture under various loads, increase the tensile strength and first crack load by bridging across the cracks. Enhanced properties of fibre reinforced concrete depends on the quantity and type of fibres used, Divya, et al. 2010 [1]. Fibre reinforced concrete finds typical application in industrial floors, pavements, tunnel linings, refractory linings, seismic resistant structures, dam construction, repair and rehabilitation of marine structures and in conventional RC frames, Alireza, et al. 2014 [9]. Even though different fibres such as glass, plastic, polypropylene have been evaluated as reinforcement in concrete, steel fibre is the most commonly used fibre owing to high toughness and resistance to static and dynamic loads. Holschemacher, et al. [10].The elongated shape and large surface area of fibres affects the workability of SCC and the severity depends on the type and dosage of fibre used. Optimum quantity of fibre dosage should be arrived, maintaining good flow and passing ability, Deeb, et al. 2012 [11].

\section{Research Significance}

Systematic mix design procedure is required for the production of quality SCC. Enormous research was done in the past with SCC but few studies with the utilization of steel fibres in self-compacting concrete were studied. Also, limited studies with steel fibre reinforced self-compacting concrete using M-sand and GGBS (SCM) for improving the paste properties of SCC. Due to environmental consequences and scarcity of river sand, usage of M-sand has to be encouraged. In the current study, a mix design methodology is proposed based on packing concept incorporating steel fibres and using M-sand as fine aggregate. Properties of the developed mixes were analysed for fresh and hardened properties. The significance of the research is to assess the suitability of M-sand and to evaluate the fresh \&hardened properties, so that the proposed methodologies can beneficiate for field applications. The present research work proposes simplified concrete mix design methodologies for developing a self-consolidating concrete with the incorporation of steel fibres and M-sand.

\section{Design Principles for SCC}

The research strategy of SFRSCC using M-sand was divided into 3 phases. In the first phase, a new method of mix design methodology was developed based on packing density concept. Maximum packing density was achieved using aggregate and the powder phase using slump cone studies and Puntke test. Three different mixes (M1, M2\&M3) were developed, varying the w/p ratios and the assessment of fresh 
properties was carried out for the designed mixes. In the second phase, optimization of steel fibre volume fraction $\left(\mathrm{V}_{\mathrm{f}}\right)$ was carried out for M1, M2 and M3, by adding different volume fractions of steel fibres and evaluating the flow properties using slump cone studies. With the optimized $V_{f}$ of steel fibres, characterization of fresh properties for each mixes were carried out. The third phase consists of studying the hardened properties of developed SCC with and without fibres. Investigated properties are compressive strength, tensile strength and modulus of elasticity and their effects at different ages of concrete $(3,7$ and 28 days).

\section{Proposed Mix Design Methodology}

The right selection of concrete ingredients and their optimized proportions is essential for obtaining a selfcompacting fibre reinforced concrete which can provide high flowability, segregation resistance and bleeding .In the present investigation, particle packing concept were used for optimization of various ingredients. The basic idea of the proposed mix design methodology is to arrive at maximum packing density, for aggregates and powder phase which will result in improved fresh and hardened properties. A tailored adaption of the test procedure described in ASTM C29 [12] was used for determining the packing density of aggregates. Packing density of aggregates was arrived by using slump cone and powder by conducting Puntke test. Optimized dosage of SP was arrived by Marsh cone studies. The reactivity of cement and slag was confirmed by conducting Slag Activity Index (SAI). Steel fibres were added to enhance the mechanical properties and were optimized by carrying out flow studies.

The procedure for the proposed mix design methodology is summarized in the following steps:

\subsection{Step 1: Fixing the Optimized Combination of Coarse aggregates}

For determining the optimized quantity of coarse aggregate combinations $(12.5 \mathrm{~mm}$ and $20 \mathrm{~mm})$, the packing density was determined for different combinations of 12.5 and $20 \mathrm{~mm}$ aggregates. The percentage of 12.5 and $20 \mathrm{~mm}$ aggregates was varied from 0 to $100 \%$ (with an increment of $10 \%$ ) by volume.

$$
\text { Packing density }=((\mathrm{M} 1 / \mathrm{S} 1)+(\mathrm{M} 2 / \mathrm{S} 2)) /(\mathrm{Vc})
$$

Where, M1\&M2 = Mass of each aggregate type; $\mathrm{S} 1 \& \mathrm{~S} 2=$ Specific gravity of equivalent aggregate type; Vc $=$ Volume of the container.

The combination which gave the maximum packing density was identified as the optimised combination and was further used for determining the quantity in step 2.

\subsection{Step 2: Optimization of Combination of Coarse Aggregates, M-Sand and Determination of the Void Content}

For optimizing the aggregate $(12.5,20 \mathrm{~mm}$ and $\mathrm{M}$-sand) combination, M-sand content was varied from 40 $60 \%$ (increment of $10 \%$ ) by volume. The range of Fine aggregate (M-sand) was selected based on EFNARC guidelines [13].

$$
\text { Packing density }=((\mathrm{M} 1 / \mathrm{S} 1)+(\mathrm{M} 2 / \mathrm{S} 2)+(\mathrm{M} 3 / \mathrm{S} 3)) /(\mathrm{Vc})
$$

where M1, M2 \& M3 = Mass of each aggregate type; S1 ,S2 \& S3 = Specific gravity of corresponding aggregate type; $\mathrm{Vc}=$ Volume of the container.

$$
\text { Void content }=1 \text { - packing density }
$$

\subsection{Step 3: Calculation Of Paste Volume Based on Required Slump Flow}

The obtained void content in step 2 indicates the theoretical volume of paste required to fill the voids. An empirical relation, Nanthagopalan, et al., 2009 [14] was used to determine the volume of paste, based on void content and required slump flow.

$$
\text { Volume of paste }=\text { Void volume }+(\text { required slump flow }-321) / 4.068
$$

The above relation will provide only an indication of paste volume for the required slump flow, which will help in reducing the number of trials. 


\subsection{Step 4: Fixing the Aggregate Volume}

Total concrete volume $=10001$

Normally $2 \%$ air content is assumed for scc (201)

Net concrete volume $=1000-20=9801$

$9801=$ volume of paste + Volume of aggregate

Vol of aggregate $=980$ - Volume of paste

\subsection{Step 5: Fixing the w/p Ratio \& Calculation of Powder Volume}

The $\mathrm{w} / \mathrm{p}$ ratio by volume can be fixed based on the compressive strength requirements. Volume of the paste can be expressed as:

Volume of paste $=$ volume of powder volume of water

(Volume of powder $=$ volume of cement volume of supplementary cementitious materials)

From the selected w/p ratio, volume of powder was determined.

\subsection{Step 6: Fixing the Optimum Combination of Powder Content}

The concept of packing density was used to optimize the powder (Cement : GGBS) combination and was determined from Puntke test. The procedure of Puntke test is explained elsewhere, Nanthagopalan 2006 [15]. Packing density of cement:GGBS was determined for different combinations, varied from 0 to $100 \%$ (with an increment of $10 \%$ ) by volume.

$$
\text { Packing density }=1-(\mathrm{Vw}) /(\mathrm{Vp} / \mathrm{Vw})
$$

$\mathrm{Vw}=$ Volume of water $(\mathrm{cm} 3), \mathrm{Vp}=$ Volume of Particle $(\mathrm{cm} 3)$

The powder combination which gave maximum packing density was selected. The reactivity of slag and cement for the resultant combination was confirmed by conducting slag activity index.

\subsection{Step 7: Calculation of Superplasticizer Dosage}

The optimised dosage of superplasticizer was arrived by conducting Marsh cone studies [16], for the selected powder combinations and $\mathrm{w} / \mathrm{p}$ ratio.

\subsection{Step 8: Assessment of Fresh Properties}

Trial mixes must be carried out based on the proportions calculated. Characterisation of SCC at fresh stage is based on EFNARC specifications [13].

\subsection{Step 9: Adjusting the Mixture Proportion}

Based on the test results obtained from step (8) the EFNARC specifications is checked for the designed concrete otherwise, proper adjustments are made until the concrete achieves satisfactory results.

\subsection{Step10: Optimisation of Steel Fibre Content}

Optimisation of steel fibres was carried out by conducting slump flow studies. Different volume fractions of steel fibres can be used for the mix obtained from step (9). The flow which gives at least $600 \mathrm{~mm}$ spread diameter and homogenous distribution of concrete fibres along the flow is considered as the optimum volume fraction of steel fibres.

\section{Experimental}

\subsection{Materials Used}

The materials used for the present study are detailed below and shown in Fig. 1. 


\subsubsection{Cement}

Ordinary Portland cement (OPC) of 53 grade was used for all the mixes, confirming to IS specifications [17].The fineness of the cement was $320 \mathrm{~m}^{2} / \mathrm{kg}$ with a specific gravity of 3.15 .

\subsubsection{Ground granulated blast furnace slag (GGBS)}

GGBS used for the current study is having a fineness of $450 \mathrm{~m}^{2} / \mathrm{kg}$ and a specific gravity of 2.9.

\subsubsection{Coarse aggregate}

Two different types of coarse aggregates were used for the present investigation with maximum sizes of 12.5 and $20 \mathrm{~mm}$. The properties of the selected aggregates were confirming to IS specifications [18-19].The specific gravities of 12.5 and $20 \mathrm{~mm}$ aggregates are 2.8 and 2.78 respectively.

\subsubsection{Manufactured sand (M-sand)}

Locally available M-sand was used for the study, well graded sand falling under Zone-II category as per Indian specifications [18].The specific gravity and bulk density were found to be 2.6 and $14.95 \mathrm{kN} / \mathrm{m}^{3}$.

\subsubsection{Super plasticiser}

A polycarboxylic ether based high range water reducer with a solid content of $40 \%$ was used. The specific gravity is between 1.09-1.11 (manufacturer data sheet).

\subsubsection{Steel fibres}

Glued steel fibres conforming to ASTM - 820 \& EN-14889 standards were used. The aspect ratio of the fibres is 65 and the tensile strength is $1100 \mathrm{MPa}$.

\subsubsection{Water}

Potable water free from chlorides and sulphates was used for mixing as well as for curing the concrete.

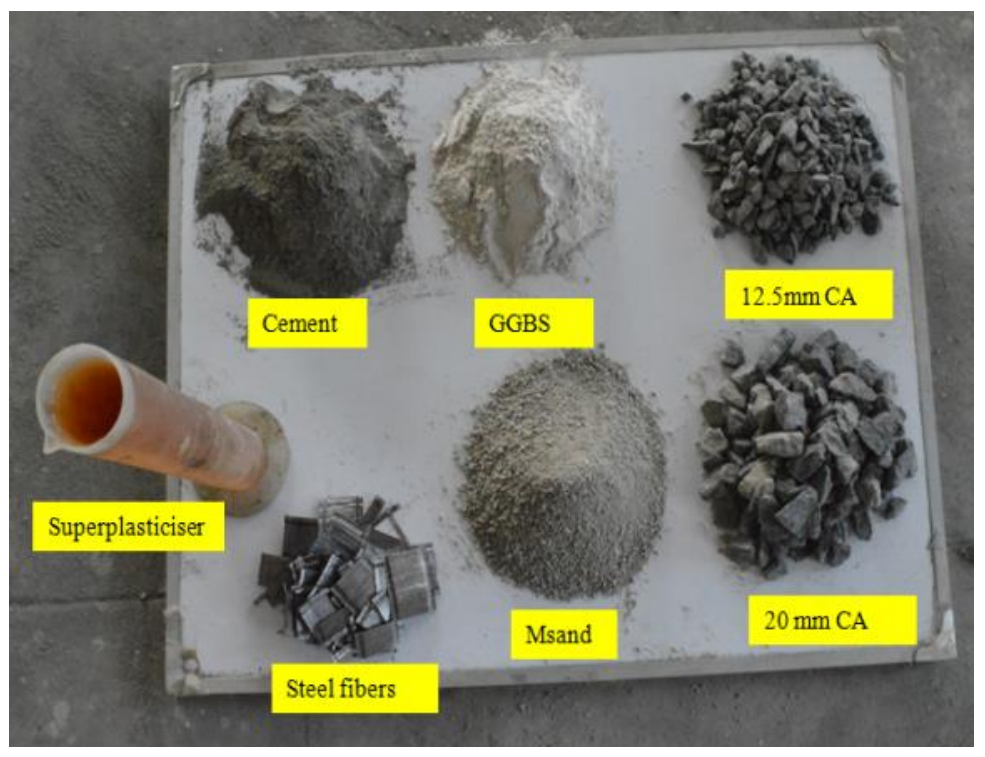

Fig. 1. Materials used in this investigation. 


\subsection{Packing Density of Aggregates}

The performance of concrete mix (fresh and hardened) depends primarily on the packing density of ingredients. In the present study, a simple procedure was used for determining the packing efficiency of aggregates. Slump cone apparatus was used for determining the packing density of aggregates which has $10 \mathrm{~cm}$ top diameter, $20 \mathrm{~cm}$ bottom diameter and $30 \mathrm{~cm}$ height. Initially, the proportions of individual aggregates were fixed in terms of volume and thereafter converted to weight. Aggregates are weighed and kept in separate trays (Fig. 2). In order to achieve a proper blending of aggregates, the aggregates were mixed manually. After achieving proper blending (Fig. 3), the mixed aggregates are poured from a constant height $(30 \mathrm{~cm})$ to the slump cone in a single pour, without any compaction. To achieve a constant height and to ensure efficient filling of aggregates, an inverted slump cone with same dimension was kept on top (Fig. 4). After placing the aggregates, inverted cone is taken off. The top of the slump cone was levelled and excess aggregates were levelled off (Fig. 5).The total mass occupied by the aggregates in the slump cone was noted down. By evaluating the total mass and the volume occupied by each aggregates, the mass of individual aggregates was found out. Finally packing density and void content was calculated by using Eqns. (1), (2) and (3).

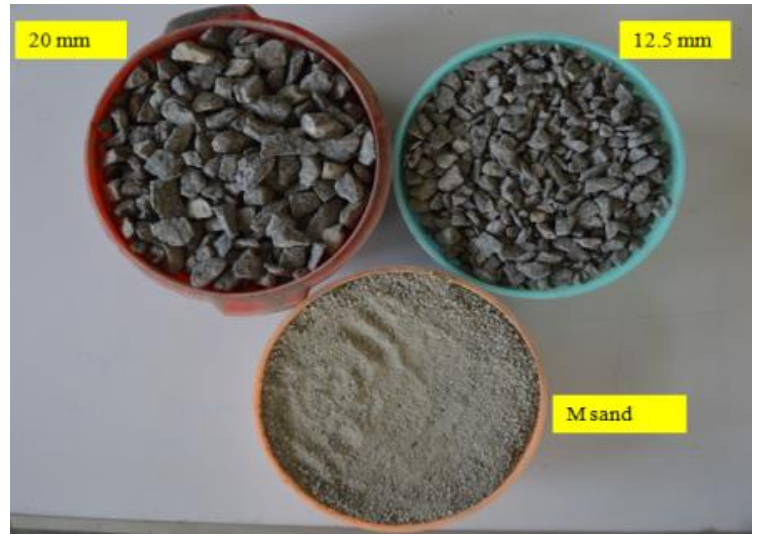

Fig. 2. Snap shot of coarse aggregates and M-sand.

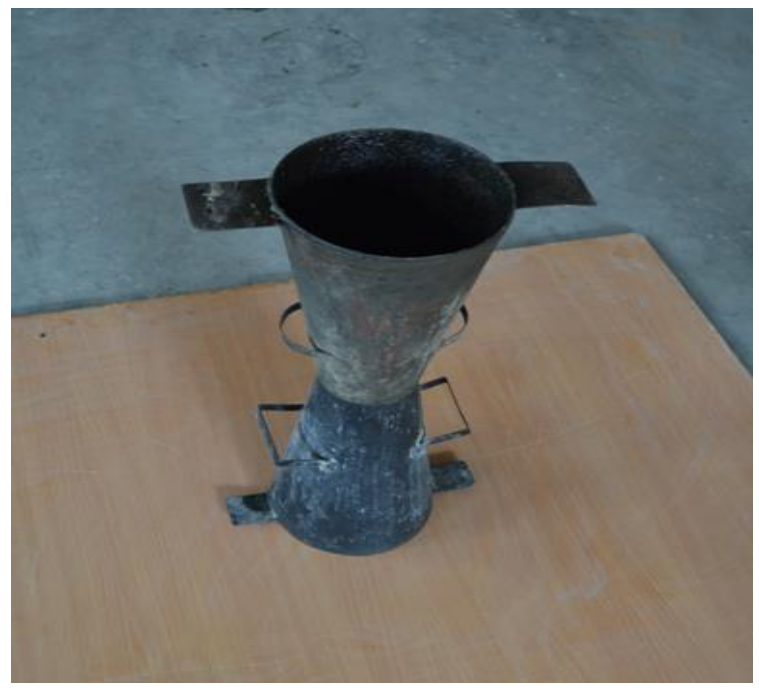

Fig. 4. Slump cone filling for packing density.

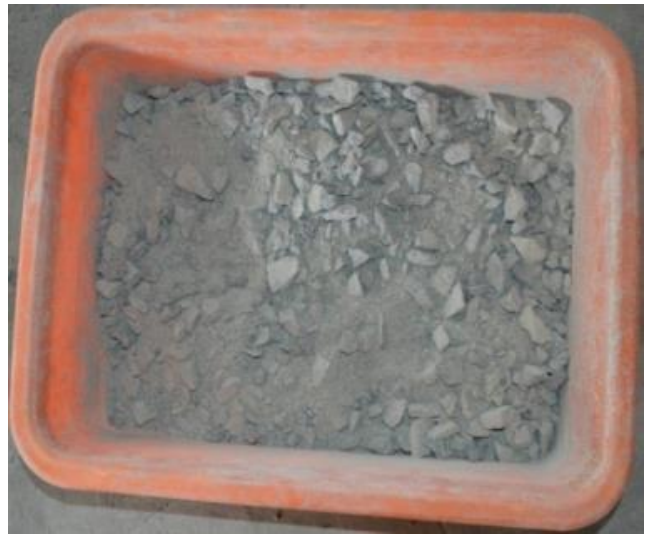

Fig. 3. Snapshot after mixing aggregates.

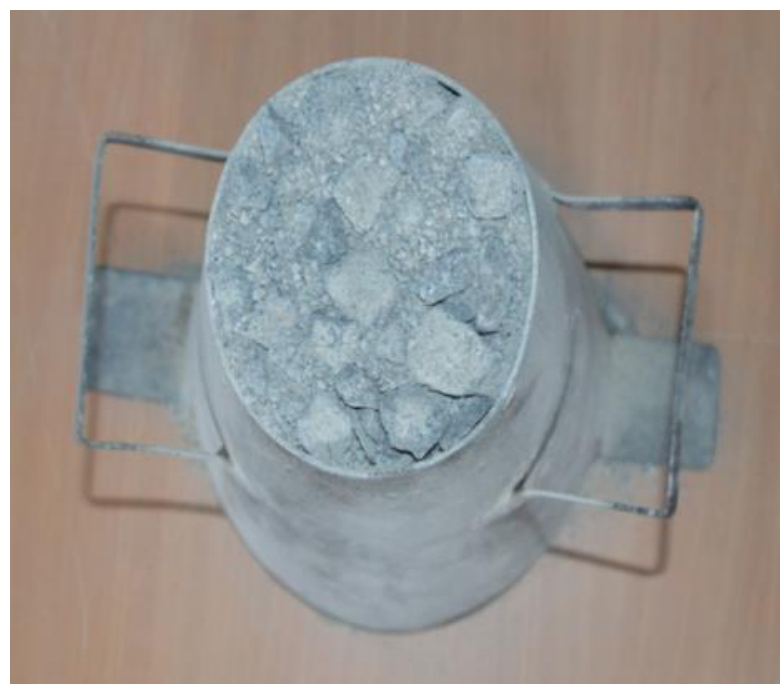

Fig. 5. Packing modulus of dry concrete ingredients.

\subsection{Optimization of Powder Combination}

Puntke test was used to optimize the powder (Cement:GGBS) combinations. The fundamental theory of Puntke test is that the water when added to the dry materials fills the voids between the particles and acts as lubricant to make the materials to compact efficiently. The water which is excess after completely filling the voids will be on the surface indicating the saturation limit. The required mass of the cementitious materials was placed in a beaker and mixed thoroughly for homogenisation. Once the homogeneity is achieved, water 
is added. Water is added gradually to the mixture and mixed with a stirrer until it acquires a plastic state after repeated tapping of the container. Following this, water is added drop by drop with a pipette, mixing carefully, until the saturation point is reached. At this point, the surface smoothens itself after repeated tapping of the beaker till the bleed water appears on the surface. The experiment was repeated for 3 times to get the least water required to achieve saturation. From the volume of water used, the packing density was determined by using the Eq. (7).

\subsection{Slag Activity Index (SAI)}

The significance of SAI is to determine the range of strength of slag with the different replacement levels of cement. The acceptance of mineral admixture is confirmed by comparing the compressive strength of mortar containing the mineral component to that of plain cement mortar. The test procedures for SAI are explained elsewhere [20-21].

\subsection{Optimization of Steel Fibre Dosage}

Slump flow studies were used for optimizing the volume fraction of steel fibre dosage. The apparatus used for the experiment is a slump cone with $10 \mathrm{~cm}$ top diameter, $20 \mathrm{~cm}$ bottom diameter and $30 \mathrm{~cm}$ height. Three mixes (M1, M2 \& M3) which was arrived based on steps 1 to 9 was selected. Three different volume fractions were tried for each mix; $0.50 \%, 0.75 \% \& 1.00 \%$ by volume of concrete. Slump flow studies were conducted for each mix with different volume fractions of fibres. The volume fraction of fibres which provide a minimum of $600 \mathrm{~mm}$ flow diameter without bleeding, segregation and clustering of fibres were selected.

\subsection{Mixing Procedure}

An effective mixing procedure leads to a homogeneous mix, which is the prerequisite for trustworthy test results. The influence of mixing procedure and mixing time plays a key role in developing a homogenous SCC as compared to conventionally vibrated concrete (CVC). The literature studies, Buquan, et al. 2003, Patric, et al. 2008, Grunewald 2006 and Sahmaran, et al. 2007 [22-25] contribute to the knowledge that, each mixture proportion has got its own mixing sequence, percentage of water and chemical admixtures added with time and total time of mixing. A small change in mix procedure may affect the rheological behaviour of freshly mixed SCC. The following mix procedure is adopted for the study, initially the coarse aggregate $(12.5 \mathrm{~mm}$ and $20 \mathrm{~mm})$ were added and allowed to mix for $30 \mathrm{sec}$ followed by M-sand for $45 \mathrm{sec}$ mixing. After this, Powder (cement+GGBS) was added and kept mixing for $45 \mathrm{~min}$. In the next step, steel fibres were introduced slowly and continuously into the dry mix and proper distribution of fibres is ensured without balling. The mixing time was kept for 30secs and the mixing of $80 \%$ of the water is added slowly and after the addition, a mixing time of $45 \mathrm{sec}$ is given. Water $(20 \%)$ is premixed with superplasticizer and was added at 3 different stages. The time elapsed between three stages were 30 seconds and the mixing was continued for about 2 min after all the ingredients added. The mixture is then ready for filling and the resulting mix with the above procedure yields a homogenous concrete with adequate flowability and segregation resistance.

\subsection{Casting and Testing Methodology}

In the present study, six different concrete mixes were considered for evaluation out of which three mixes with fibres and 3 without fibres. The various volume fractions $\left(V_{f}\right)$ used are 0.5 and $0.75 \%$, which is based on concrete volume. The concrete mix design is given in Table 1 and the fresh properties were assessed based on EFNARC specifications, which includes slump flow and J-ring. Hardened properties were studied using standard specimens of size $100 * 100 * 100 \mathrm{~mm}$ cubes (compressive strength), $150 * 300 \mathrm{~mm}$ cylinder (elastic modulus) and 100*200 mm cylinder (tensile strength). After filling the mould, the casting surface was levelled and finished using a trowel. The moulds were kept undisturbed for 24hrs. After 24hrs, the moulds are remolded and the specimens were immersed in water for curing under controlled environment. All the hardened properties of concrete specimens were investigated at 3, 7 and 28 days and the tests was performed as per IS 516 [26]. 
Table 1. Mix proportion of SCC.

\begin{tabular}{|c|c|c|c|c|c|c|c|c|c|}
\hline Mix ID & $\left(\mathrm{v}_{\mathrm{f}}\right)$ & $\begin{array}{c}\text { Vol: } \\
\text { of } \\
\text { cement }\end{array}$ & $\begin{array}{c}\text { Vol: } \\
\text { of } \\
\text { GGBS }\end{array}$ & $\begin{array}{c}\text { Vol: } \\
\text { of } \\
\text { water }\end{array}$ & $\begin{array}{c}\text { Vol: } \\
\text { of } \\
\text { paste }\end{array}$ & $\mathbf{w} / \mathbf{p}$ & $\begin{array}{c}\text { Vol: } \\
\text { of CA } \\
(12.5 \mathrm{~mm})\end{array}$ & $\begin{array}{c}\text { Vol: } \\
\text { of CA } \\
(20 \mathrm{~mm})\end{array}$ & $\begin{array}{c}\text { Vol: } \\
\text { of } \\
\text { M-sand }\end{array}$ \\
\hline $\mathrm{M} 1+0 \%$ & $0.00 \%$ & 134 & 90 & 156 & 380 & 0.7 & 120 & 180 & 300 \\
\hline $\mathrm{M} 1+0.5 \%$ & $0.50 \%$ & 134 & 90 & 156 & 380 & 0.7 & 120 & 180 & 300 \\
\hline $\mathrm{M} 2+0 \%$ & $0.75 \%$ & 120 & 80 & 180 & 380 & 0.9 & 120 & 180 & 300 \\
\hline $\mathrm{M} 2+0.75 \%$ & $0.75 \%$ & 120 & 80 & 180 & 380 & 0.9 & 120 & 180 & 300 \\
\hline M3+0\% & $0.75 \%$ & 109 & 72 & 199 & 380 & 1.1 & 120 & 180 & 300 \\
\hline $\mathrm{M} 3+0.75 \%$ & $0.75 \%$ & 109 & 72 & 199 & 380 & 1.1 & 120 & 180 & 300 \\
\hline
\end{tabular}

\section{Results \& Discussion}

\subsection{Packing Density of Aggregates}

\subsubsection{Packing density of coarse aggregate}

In order to determine the optimum packing density of coarse aggregate combination (12.5 and $20 \mathrm{~mm})$, the combination of aggregates were varied from $0-100 \%$ by volume with an increment of $10 \%$. Packing densities of each combination were determined from Eq. (1) and the results are presented in Table 2.

Table 2. Packing density for coarse aggregate combination.

\begin{tabular}{|c|c|c|c|c|c|c|c|c|}
\hline Name & $\begin{array}{c}\% \text { vol } \\
12.5 \mathrm{~mm}\end{array}$ & $\begin{array}{l}\% \text { vol } \\
20 \mathrm{~mm}\end{array}$ & $\begin{array}{c}\text { Weight } \\
\text { (kg) }\end{array}$ & $\begin{array}{l}\text { M1(kg) } \\
12.5 \mathrm{~mm}\end{array}$ & $\begin{array}{c}\text { M2(kg) } \\
20 \mathrm{~mm}\end{array}$ & M1/S1 & M2/S2 & $\begin{array}{c}\text { Packing } \\
\text { density } \\
(\%)\end{array}$ \\
\hline A1 & 0 & 100 & 7.55 & 0.00 & 7.55 & 0.00 & 2.72 & 49 \\
\hline A2 & 10 & 90 & 7.65 & 0.76 & 6.88 & 0.27 & 2.48 & 50 \\
\hline A3 & 20 & 80 & 7.86 & 1.57 & 6.29 & 0.56 & 2.26 & 51 \\
\hline A4 & 30 & 70 & 7.92 & 2.38 & 5.55 & 0.85 & 2.00 & 52 \\
\hline A5 & 40 & 60 & 7.96 & 3.18 & 4.78 & 1.14 & 1.72 & 52 \\
\hline A6 & 50 & 50 & 8.1 & 4.05 & 4.05 & 1.45 & 1.46 & 53 \\
\hline A7 & 60 & 40 & 7.98 & 4.79 & 3.19 & 1.71 & 1.15 & 52 \\
\hline A8 & 70 & 30 & 7.92 & 5.54 & 2.38 & 1.98 & 0.85 & 52 \\
\hline A9 & 80 & 20 & 7.78 & 6.23 & 1.56 & 2.22 & 0.56 & 51 \\
\hline A10 & 90 & 10 & 7.76 & 6.99 & 0.78 & 2.49 & 0.28 & 50 \\
\hline A11 & 100 & 0 & 7.47 & 7.47 & 0.00 & 2.67 & 0.00 & 49 \\
\hline
\end{tabular}

Referring to Fig. 6, it is observed that the packing densities of $12.5 \mathrm{~mm}$ and $20 \mathrm{~mm}$ aggregates show a characteristic trend with maximum density at optimum point. As the volume of smaller size aggregate $(12.5 \mathrm{~mm})$ increases, the packing density becomes more effective up to a combination of 50:50 (53\%). After this combination, a decline in packing density was observed.

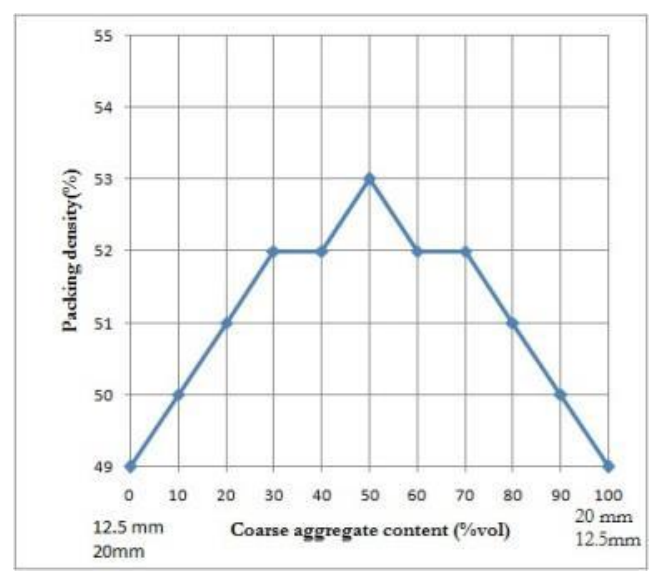

Fig. 6. Coarse aggregate content vs. packing density. 


\subsubsection{Packing density of coarse aggregate \& M-sand}

Packing density of combined aggregate combination (12.5, 20mm and M-sand) needs to be evaluated, for determining the void content. Void content indicates the amount of paste required to fill the voids. The aggregate combination with maximum packing density will persuade the behavior of concrete. In order to study the effect of packing densities, wide- range of combinations of $\mathrm{M}$-sand and coarse aggregates were considered. Normally for SCC with fine to coarse aggregate ratio of $\geq 1$ and based on this the M-sand to CA volume was varied with 40:60, 50:50 \& 60:40. Even though the maximum packing density for 12.5 and $20 \mathrm{~mm}$ coarse aggregate combination was $50: 50$ by volume, for the better understanding of packing densities coarse aggregate combinations was considered for 50:50,60:40,40:60 by volume. Results obtained using Eq. (2) are presented in Table 3.

Table 3. Packing density for coarse aggregates and M-sand combination.

\begin{tabular}{|c|c|c|c|c|c|c|c|c|c|}
\hline Name & $\begin{array}{c}\% \\
\text { vol } \\
\text { CA }\end{array}$ & $\begin{array}{c}\% \text { vol } \\
12.5 \mathrm{~mm}\end{array}$ & $\begin{array}{l}\% \text { vol } \\
20 \mathrm{~mm}\end{array}$ & $\begin{array}{c}\% \\
\text { vol } \\
\text { M- } \\
\text { sand }\end{array}$ & $\begin{array}{l}\text { Weight } \\
\text { (kg) }\end{array}$ & $\begin{array}{l}\text { M1(kg) } \\
12.5 \mathrm{~mm}\end{array}$ & $\begin{array}{l}\text { M2(kg) } \\
20 \mathrm{~mm}\end{array}$ & $\begin{array}{c}\text { M3(kg) } \\
\text { M- } \\
\text { sand }\end{array}$ & $\begin{array}{c}\text { Packing } \\
\text { density } \\
(\%)\end{array}$ \\
\hline A1 & \multirow{3}{*}{60} & 30 & 30 & \multirow{3}{*}{40} & 9.65 & 2.90 & 2.90 & 3.86 & 65 \\
\hline A2 & & 36 & 24 & & 9.65 & 3.47 & 2.32 & 3.86 & 65 \\
\hline A3 & & 24 & 36 & & 9.8 & 2.35 & 3.53 & 3.92 & 66 \\
\hline B1 & \multirow{3}{*}{50} & 25 & 25 & \multirow{3}{*}{50} & 9.81 & 2.45 & 2.45 & 4.91 & 66 \\
\hline B2 & & 30 & 20 & & 9.80 & 2.94 & 1.96 & 4.90 & 66 \\
\hline B3 & & 20 & 30 & & 10.01 & 2.00 & 3.00 & 5.01 & 68 \\
\hline C1 & \multirow{3}{*}{40} & 20 & 20 & \multirow{3}{*}{60} & 9.43 & 1.89 & 1.89 & 5.66 & 64 \\
\hline $\mathrm{C} 2$ & & 24 & 16 & & 9.45 & 2.27 & 1.51 & 5.67 & 64 \\
\hline C3 & & 16 & 24 & & 9.40 & 1.50 & 2.26 & 5.64 & 64 \\
\hline
\end{tabular}

The obtained results indicate only marginal variations in packing densities with different $\mathrm{M}$-sand combinations. For the combination of aggregate with $40 \& 50 \% \mathrm{M}$-sand, maximum packing densities are achieved when $20 \mathrm{~mm}$ aggregates are higher. From the table it is observed that, lower packing density $(64 \%)$ is for combination of coarse aggregate and $60 \% \mathrm{M}$-sand. The maximum packing density reported is for combination of 20:30:50 (12.5mm, 20 mm, M-sand), ie M-sand/coarse aggregate ratio is 1. It should also be noted that , the maximum packing density of aggregate $(12.5 \& 20 \mathrm{~mm})$ with $\mathrm{M}$-sand is for 40:60.Referring to Table 1 the max packing density for 50:50 combination was $53 \%$ and for $40: 60$ is 52 , very less variation which is acceptable.

\subsubsection{Optimization of powder and super plasticizer dosage}

The optimized quantity of Cement and GGBS was arrived by performing Puntke test. From the studies, the optimized combination of Cement:GGBS was found to be $60: 40$ (packing density $50.5 \%$ ) by volume. Studies on Slag activity index confirmed the reactivity index of Cement:Slag (60:40) and observed that the reactivity index is found to be decreased, when the replacement levels are more than $40 \%$.Marsh cone studies were conducted to optimize the dosage of superplasticizer for different $\mathrm{w} / \mathrm{p}$ ratios. Optimum dosage of superplasticiser is the dosage beyond which the flow time does not decrease appreciably. The optimum dosage of various mixes by the combined weight of cement and GGBS are M1 (2\%), M2 (1 \%) \&M3 $(0.5 \%)$.

\subsection{Characterization of Fresh Properties}

Self compactability cannot be assessed using a single test method, usually requiring more than one method, Dinakar, et al. 2013 [27].The present investigation evaluated the self compactability of the designed mix by Slump flow studies for flow ability and segregation resistance and J ring for passing ability. It is well know that fibre affects the characteristics of SCC in the fresh state. In order to reduce the effect of fibres on fresh properties, careful optimization techniques and placing of fibres need to be adopted. Table 4 details the fresh properties of SCC with and without fibres. Slump flow test is a measure of horizontal free flow(deformation) in the absence of obstructions. Higher slump fow indicates the ability of the concrete to 
fill the formwork under its own weight. Inspite of varying w/p ratio and SP dosage, all the mixes without fibres are giving a spread diameter above $700 \mathrm{~mm}$ and in the range of $610-660 \mathrm{~mm}$ with fibres

Table 4. Fresh concrete properties.

\begin{tabular}{lccc}
\hline Mix ID & Slump flow $(\mathbf{m m})$ & Flow time $\mathbf{T}_{\mathbf{5 0 0}}(\mathbf{s e c})$ & J ring flow $(\mathbf{m m})$ \\
\hline M1 $+0 \%$ & 710 & 4.8 & 640 \\
M $+0.5 \%$ & 610 & 5.1 & 600 \\
M $+0 \%$ & 720 & 3.2 & 670 \\
M $+0.75 \%$ & 640 & 4.0 & 620 \\
M $3+0 \%$ & 740 & 2.2 & 690 \\
M3 $+0.75 \%$ & 660 & 3.1 & 625 \\
\hline
\end{tabular}

The reason may be due to the use of high paste volume and the constant volumetric proportions of the paste and aggregates throughout the mix. This clearly indicated the influence of paste volume on the spread diameter. Even though the flow diameter was reduced with the incorporation of fibres, these values are in the range specified by EFNARC. The reason behind the decrease in flow diameter of mixes with steel fibres can be explained in such a way that, fibres are needle like particles which will enhance the resistance to flow and contribute to an internal structure in the fresh state and also due to the elongated shape of the fibre, which is higher than aggregate which creates a higher surface area at the same volume. During the time of test, it was observed that mix M3 showed a very slight indication of segregation.

Time required to reach $500 \mathrm{~mm}$ slump flow is considered as $\mathrm{T}_{500}$.It is related to the viscosity. Higher the time required, higher is the viscosity and vice-versa. All the obtained values are within the limits prescribed by the standards. Compared to all the mixes, it is seen that mix M1 is highly viscous which may be due to the use of lower w/p ratio. J ring with slump flow was conducted to assess the passing ability. All the mixes with and without fibres indicates a fair passing ability. This is due to the fact that, since the mixes employed a higher paste content, the aggregates had enough space to disperse effectively thereby avoiding the congestion at the reinforcements.

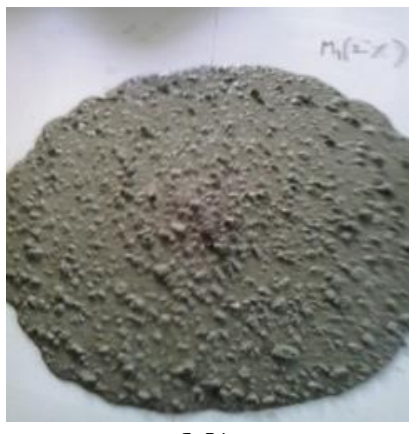

M1

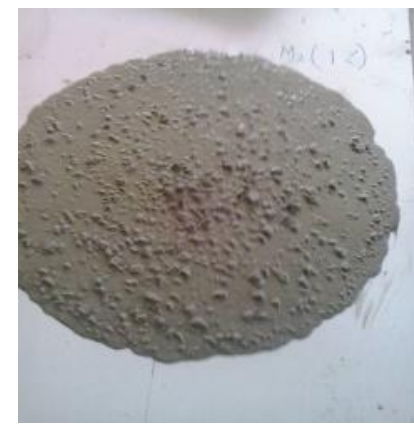

M2

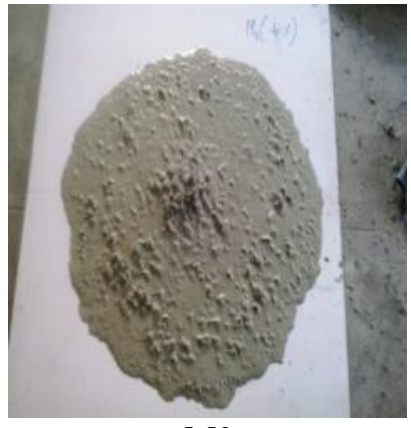

M3

Fig. 7. Images of slump flow and spread diameter studies.

\subsection{Hardened Properties of SCC}

It is imperative to understand the mechanical performance of a material under different loading conditions, especially when a new ingredient is introduced into the mix. Also a better understanding on the influence of strength parameters at different ages will add confidence, principally for safe remolding process. In the context of hardened properties, the present investigation focused mainly on compression, tensile strength and elastic modulus. All experiments were performed on three replicates, and the average values are taken for the discussion of test results. Evolution of hardened properties was analysed at 3, 7 and 28days.

\subsubsection{Compressive strength}

Compressive strength can be defined as the maximum stress a material can sustain under crush loading. Compressive strength is calculated by dividing the maximum load by the original cross-sectional area of a specimen. In the present investigation, uniaxial compression test were carried on concrete cubes of size 
$100 * 100 * 100 \mathrm{~mm}$ using a compression testing machine of capacity $2000 \mathrm{kN}$. The results obtained at different ages are given in Table 5.

Table 5. Average values of compressive strength.

\begin{tabular}{lccc}
\hline \multirow{2}{*}{ Mix ID } & \multicolumn{3}{c}{ Compressive strength(MPa) } \\
\cline { 2 - 4 } & 3 days & 7 days & 28 days \\
\hline M1+0\% & 42.50 & 60.30 & 67.80 \\
M1+0.5\% & 48.30 & 66.70 & 70.90 \\
M2+0\% & 40.20 & 49.80 & 55.00 \\
M $+0.75 \%$ & 43.40 & 54.50 & 58.60 \\
M3+0\% & 30.48 & 43.70 & 45.90 \\
M3+0.75\% & 32.50 & 45.00 & 46.20 \\
\hline
\end{tabular}

As it can be observed from Fig. 8 that, addition of fibres showed marginal contribution on the improvement in compressive strength. The average increase in cube compressive strength with the addition of steel fibres is less than $10 \%$.During compressive loading, the micro crack occurred due to the transverse tensile forces could possibly be arrested by the steel fibres, leading to the increase on the load carrying capacity. This may be the reason for the enhancement of compressive strength with the addition of steel fibres. As expected, the highest compressive strength $(70.9 \mathrm{MPa})$ obtained is for the mix with a lower w/p ratio of 0.7 . Inclusion of fibres altered the failure mode of concrete from a sudden failure to more ductile failure in which the specimen remains intact after failure. Referring to Fig. 8, it is seen that the compressive strength increases with increasing age, but the rate of increase slides down when the age of specimen increases. In general the compressive strength enhancement was observed from 3 to 7 days which was between $20-30 \%$ and from 7 to 28 days it was less than 10\%. A graph was plotted between compressive strength and w/p ratio (Fig. 9), which indicates a good correlation between compressive strength and w/p ratio was observed.

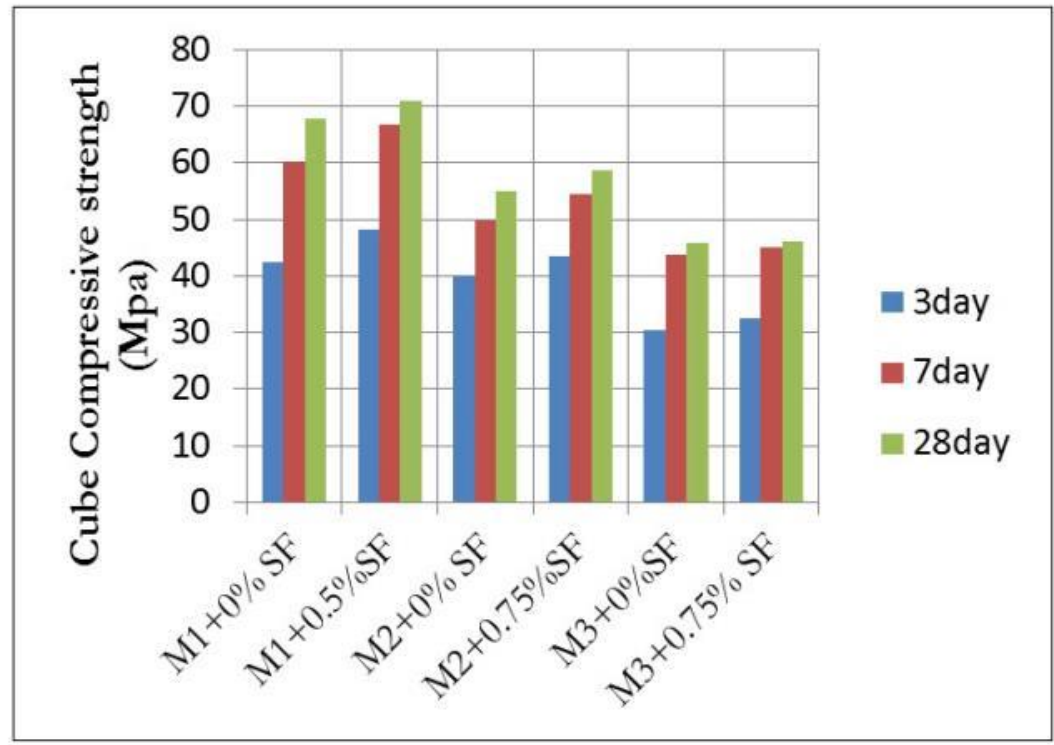

Fig. 8. Variation of compressive strength with age. 


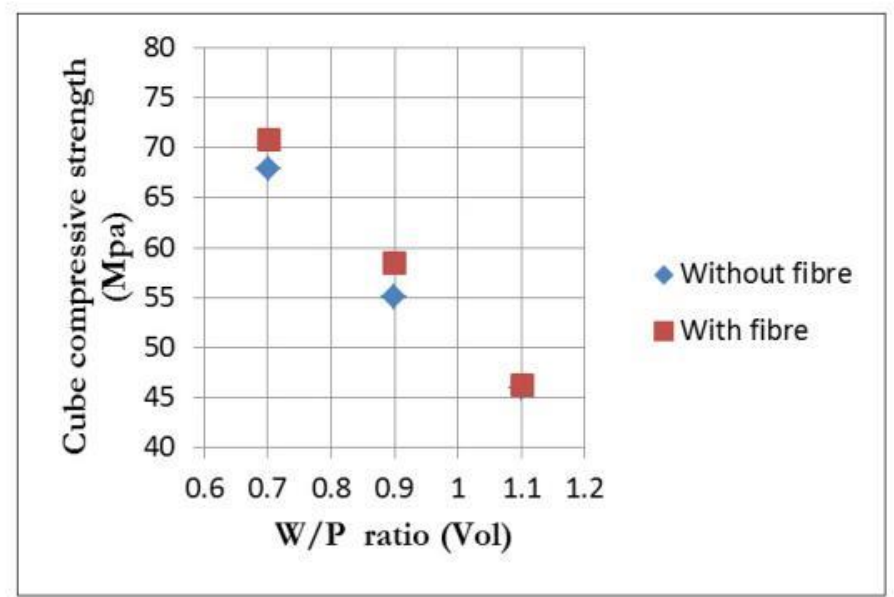

Fig. 9. Relation between cube compressive strength and w/p ratio.

\subsubsection{Tensile strength}

One of the basic properties of concrete is its tensile strength. Concrete is inherently weak in resisting the tensile forces. Addition of fibres will enhance the tensile capacity of concrete and the range of enhancement depends on various parameters. To evaluate the tensile capacity, split tensile test was carried out on $100 * 200 \mathrm{~mm}$ cylindrical specimens. The test was done by introducing a cylindrical specimen horizontally between the loading surface of the compression testing machine and the load is applied until the failure of the cylinder, along the vertical diameter. When the load is applied, vertical diameter of the cylinder is subjected to a horizontal stress of $2 \mathrm{P} / \pi \mathrm{ld}$. The obtained results are presented in Table 6.Split tensile strength results (Fig. 10) indicated a reasonable increase in tensile strength with the inclusion of steel fibres. For the same mix, the rate of increase in tensile strength is more pronounced at early ages in comparison with plain SCC. Form the results; an average increase of 30\% is observed for M1 $+0.5 \%$ steel fibres, $40 \%$ for M $2+0.75 \%$ steel fibres and only $20 \%$ for M $3+0.75 \%$.

Table 6. Average values of split tensile strength.

\begin{tabular}{lccc}
\hline \multirow{2}{*}{ Mix ID } & \multicolumn{3}{c}{ Split tensile strength(MPa) } \\
\cline { 2 - 4 } & 3 days & 7 days & 28 days \\
\hline M1+0\% & 2.83 & 3.4 & 4.4 \\
M1+0.5\% & 4.90 & 5.03 & 6.00 \\
M $+0 \%$ & 2.73 & 3.1 & 4.14 \\
M $+0.75 \%$ & 5.09 & 5.30 & 6.50 \\
M3 $+0 \%$ & 2.69 & 3.00 & 3.9 \\
M3 $+0.75 \%$ & 3.12 & 4.14 & 4.9 \\
\hline
\end{tabular}

The enhancement of tensile strength is mainly due to the resistance provided by the steel fibre against the propagation of micro cracks in the matrix. This is achieved by improving the capacity of the matrix on the overall cracking and by bridging across the minor cracks developed due to the applied load which prevents the minute crack from expanding to a major crack. During the time of testing, it was observed that the crack bridging effects of steel fibres did not allow the cylindrical specimens to split completely at failure load. 


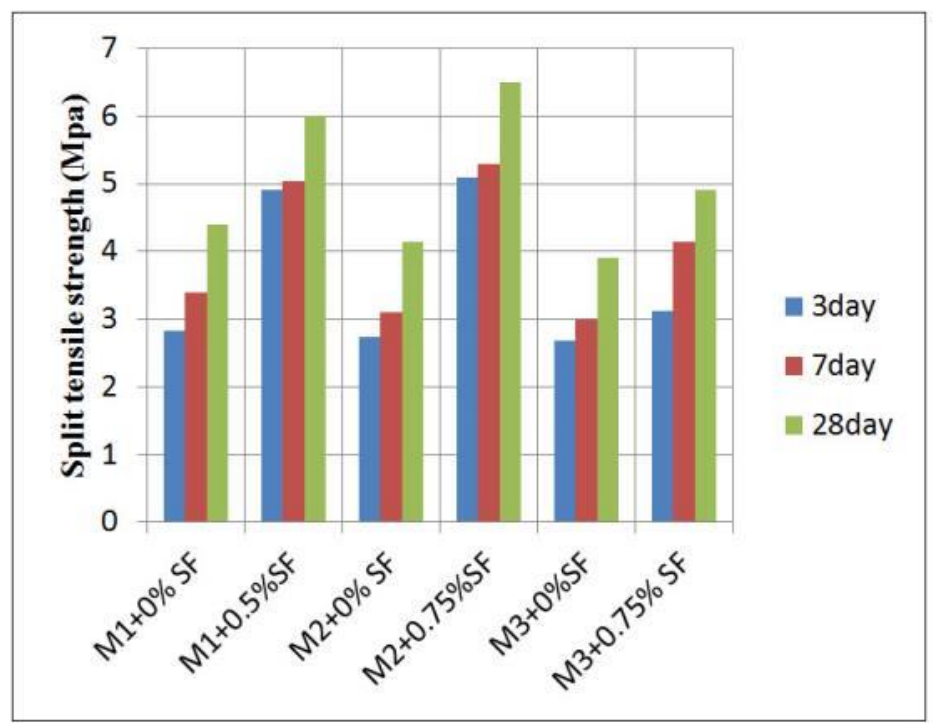

Fig. 10. Variation of split tensile strength with age of specimen.

\subsubsection{Elastic modulus}

Elastic modulus of concrete was measured to determine the resistance of the material to deformation. It was evaluated from the slope of the line drawn from the origin to a compressive stress of 0.45 times the compressive stress of concrete. The test was conducted in a compression testing machine having a maximum capacity of $2000 \mathrm{KN}$. Deformation of the cylinder was recorded by attaching it with a compressometer equipped with dial gauge. The secant modulus is obtained from the stress -strain curve and the average values are listed in Table 7. The range of elastic modulus for the various tested concrete mixes was between 28-39 GPa. It is observed from the obtained results, average increase of elastic modulus of concrete with fibres as compared to plain SCC is approximately $10 \%$.

Table 7. Average values of modulus of elasticity.

\begin{tabular}{lccc}
\hline \multirow{2}{*}{ Mix ID } & \multicolumn{3}{c}{ Modulus of elasticity (Gpa) } \\
\cline { 2 - 4 } & 3 days & 7 days & 28 days \\
\hline M1+0\% & 28 & 33 & 36 \\
\hline $\mathrm{M} 1+0.5 \%$ & 31 & 36 & 39 \\
\hline $\mathrm{M} 2+0 \%$ & 26 & 30 & 33 \\
\hline $\mathrm{M} 2+0.75 \%$ & 29 & 34 & 35 \\
\hline $\mathrm{M} 3+0 \%$ & 22 & 27 & 28 \\
\hline $\mathrm{M} 3+0.75 \%$ & 23 & 29 & 31 \\
\hline
\end{tabular}

Figure 11 exhibits the elastic modulus obtained at different ages in comparison with IS 456-2000 $(E c=5000 \sqrt{f c k})$ and European standard NF EN 1992-1-1 $E c m=22 *(f c m / 10)^{0.3}$. After comparison, it is verified that for a given compressive strength, the experimental results are lower than results obtained from codal specifications. Normally SCC employs a higher paste volume and a lower maximum size of aggregate for achieving required flowability. Modulus of elasticity of concrete depends on the modulus of elasticity of the aggregate and their volumetric proportion in concrete. The variation in results for 28 day modulus of elasticity with reference to IS 456-2000 and Eurocode 2 are 10 to $18 \%, 7$ to $22 \%$ without steel fibres and ' 6 in the case of concrete with steel fibres the variation is 7 to $9 \%$ and 2 to $12 \%$. Higher variations are observed when the strength of concrete reduces. As per IS 456-2000, actual values may differ by $\pm 20 \%$ from the values obtained using the expression. Referring to this, the obtained experimental results can be considered with high probability of occurrence. 


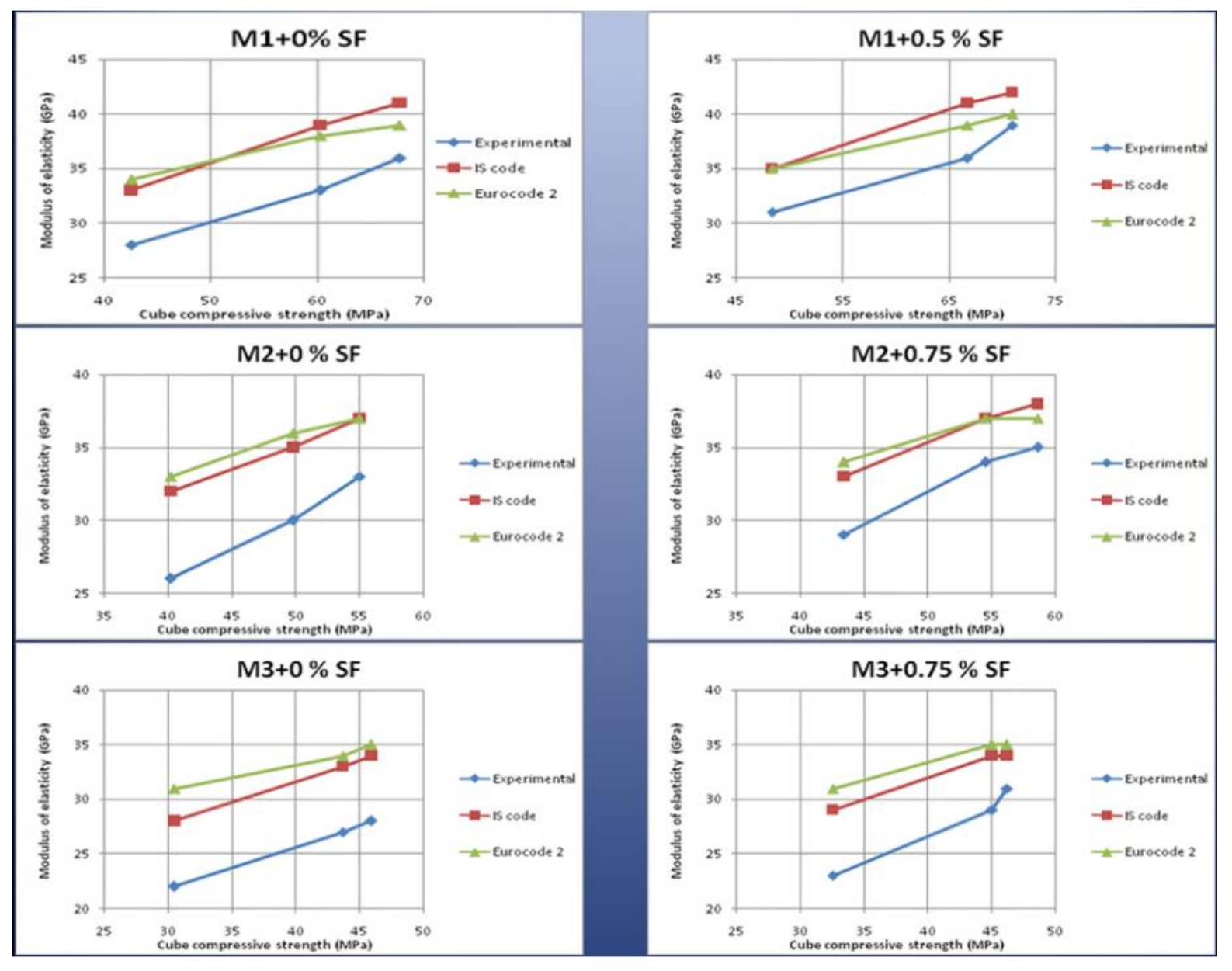

Fig. 11. Comparison of elastic modulus at various ages for different concretes.

\section{Conclusions}

This paper presents a mix design methodology for designing a SFRSCC based on packing density by replacing 100\% river sand by M-sand. The proposed mix design methodology developed based on packing density is simple and effective. Optimised combinations were arrived based on packing density concept and the combinations for $12.5 \mathrm{~mm}$ : 20mm: M-sand of 20:30:50 (maximum packing density of $68 \%$ ) and for Cement: GGBS is 60:40 (packing density of 50.5\%). Fibre dosages were optimized by slump cone studies and superplasticizer by using marsh cone. A total of six mixes were developed, three of which consisted with fibres and three without fibres. Concrete mixtures were produced with fibre volume fractions of 0.5 and $0.75 \%$ by volume of concrete. Steel fibre addition reduced the flowability and passing ability but satisfying the suggested limits for SCC. The hardened properties (compression, tension and elastic modulus) were analysed at different ages of concrete (3, 7 and 28 days). At the outset, all the properties were enhanced with age and with the addition of steel fibres. In the present investigation, range of compressive strength obtained lies between 46-70 MPa. Apart from environmental benefits, M-sand can perform the role of an effective filler material to concrete compared to river sand. M-sand used for the current study falls within the grading limits specified by IS 383 and is free from silt and clays. The present study focused on strength and workability aspects. The confidence gained through the experimental investigations from the current study can be extended for investigating more concrete parameters including toughness, effect at different curing conditions, performance at elevated temperatures, durability etc..,. In short, the developed mix design methodology offered the possibility of developing standard and high strength concrete with the addition of M-sand and the benefits of steel fibre reinforcement on the compressive strength. 


\section{References}

[1] L. Divya, M. Soman, and V. Syam Prakash, "Flexural behaviour of fibre reinforced self-compacting concrete," in Proc. of International Conference on Technological Trends (ICCT), College of Engineering, Thiruvananthapuram, 2010, pp. 303-307.

[2] The European Guidelines for Self-Compacting Concrete Specification, Production and Use, European Federation for Specialist Construction Chemicals and Concrete systems, EFNARC, 2005.

[3] P. Nanthagopalan and M. Santhanam, "A new empirical test method for the optimisation of viscosity modifying agent dosage in self-compacting concrete," Materials and Structures, vol. 43, pp. 203-212, 2010.

[4] H. Okamura, K. Maekawa, and K. Ozawa, High Performance Concrete, Gihodo Publishing, 1993.

[5] P. N. Quiroga, "The effect of the aggregates characteristics on the performance of Portland cement concrete," Ph.D. thesis, the University of Texas at Austin, 2003.

[6] B. V. Venkatarama Reddy, "Suitability of manufactured sand (M-sand) as fine aggregates in mortars and concrete," CSIC project: CP 6597/0505/11-330, 2011.

[7] P. Nanthagopalan and M. Santhanam, "Fresh and hardened properties of self-compacting concrete produced with manufactured sand," Cement and Concrete Composites, vol. 33, pp. 353-358, 2011.

[8] Specification for Coarse and Fine Aggregates from Natural Sources for Concrete, IS 383, 2002.

[9] A. Khaloo, E. Molaei Raisi, P. Hosseini, and H. Tahsiri. "Mechanical performance of self-compacting concrete reinforced with steel fibers," Construction and Building Materials, vol. 51, pp. 179-186, 2014.

[10] K. Holschemacher, T. Mueller, and Y. Ribakov, "Effect of steel fibres on mechanical properties of high-strength concrete," Materials and Design, vol. 31, pp. 2604-2615, 2010.

[11] R. Deeb, A. Ghanbari, and B. L. Karihaloo, "Development of self-compacting high and ultra-high performance concretes with and without steel fibres," Cement and Concrete Composites, vol. 34, pp. 185190, 2012.

[12] Standard Test Method for Bulk Density ("Unit Weight") and Voids in Aggregate, ASTM C 29/C 29M-27, 2003.

[13] Specification and Guidelines for Self-Compacting Concrete, EFNARC, 2002.

[14] P Nanthagopalan and M. Santhanam, "Experimental investigations on the influence of paste composition and content on the properties of self-compacting concrete," Construction and Building Materials, vol. 23, pp. 3443-3449, 2009.

[15] P. Nanthagopalan, "Investigation on the influence of granular packing on the rheological properties of cement pastes," DAAD programme, Institute of Concrete Structures and Building Materials, University of Karlsruh (TH), Germany, April-September 2006.

[16] Standard Test Method for Flow of Grout for Preplace-Aggregate Concrete-Flow Cone Method, ASTM C939, 2010.

[17] Specification for 53 grade Ordinary Portland Cement Indian Standard Code on Properties of Cement, IS 12269, 1987.

[18] Bureau of Indian Standards. Specification for Coarse and Fine Aggregates from Natural Sources for Concrete, IS383 (Second Revision), 1970.

[19] Methods of Test for Aggregates for Concrete Part 3-Specific gravity, Density, Voids, Absorption and Bulking, IS 2386, 1963.

[20] Standard Specification for Ground Granulated Blast-Furnace Slag for Use in Concrete and Mortars, ASTM C989, 1999.

[21] Standard Test Method for Compressive Strength of Hydraulic Cement Mortars, ASTM C109/C109M, 2002.

[22] B. Miao, J. C. Chern, and C.-A. Yang, "Influence of steel fibre content on properties of selfcompacting steel fibre reinforced concrete," Journal of Chinese Institute of Engineers, vol. 26, pp. 523-530, 2003.

[23] P. Stahli, R. Custer, and J. G. M. van Mier, "On flow properties, fibre distribution, fibre orientation, and flexural behaviour of FRC," Materials and Structures, vol. 41, pp. 189-196, 2008.

[24] S. Grunewald, "Performance-based design of self-compacting fibre reinforced concrete," Ph.D. thesis, Delft University, 2006.

[25] M. Sahmaran and I. O. Yaman, "Hybrid fiber reinforced self-compacting concrete with a high-volume coarse fly ash," Construction and Building Materials, vol. 21, pp. 150-156, 2007.

[26] Methods of Tests for Strength of Concrete, IS 516, 1959. 
[27] P. Dinakar, K. P. Sethy, and U. C. Sahoo, "Design of self-compacting concrete with ground granulated blast furnace slag," Materials and Design, vol. 43, pp. 161-169, 2013. 